\title{
Fabrication of nano- or micro-powder for hydroxyapatite particles derived from bovine bone
}

\author{
Van Linh $\mathrm{Ha}^{1,}$, , Diem Ngoc Thi Mai ${ }^{2}$, Huu Tien $\mathrm{Cao}^{2}$
}

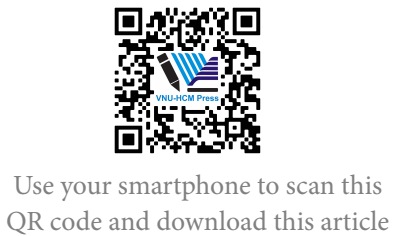

\begin{abstract}
Background: Hydroxyapatite (HA) from bovine bone has been shown to have bone regenerative capability and therefore has potential benefits in bone grafting. However, the extraction procedures are often time-consuming and labor intensive. Therefore, this study aimed to devise a simple process to fabricate HA particles from bovine bone with the potential to be used in bone tissue engineering. Methods: In this study, the simple process combined physical and chemical methods to remove numerous organic components, followed by annealing at $600^{\circ} \mathrm{C}$ to fabricate small crystal HA particles. The organic presence in the HA product was detected by Fourier-transform infrared (FTIR) spectroscopy. The particle size, interconnected porous structure, and the calciumto-phosphorous molar ratio (Ca/P) were examined by $X$-ray powder diffraction method (XRD), scanning electron microscope (SEM), and energy dispersive X-ray (EDX) analysis. Results: The combination method completely removed the organic composition. The results of SEM, XRD, and FTIR demonstrated the formation and preservation of small (nanometer sized) crystal HA particles with the porous structure. The Ca/P ratio was similar to that for natural bone. Conclusion: Pure natural HA crystals could be extracted from bovine bone. The combination of chemical and thermal decomposition methods was effective in producing HA particles. The method proposed herein has the advantage of being simple and relatively inexpensive, thereby rendering it beneficial for large-scale application.
\end{abstract}

Key words: Hydroxyapatite, HA particle, bovine bone, annealing, sintering, thermal decomposition

${ }^{1}$ Faculty of Material Science and Technology, VNUHCM-University of Science,

${ }^{2}$ Faculty of Dentistry in Pham Ngoc Thach University of Medicine

\section{Correspondence}

Van Linh Ha, Faculty of Materials Science and Technology, University of Science, Ho Chi Minh City, Viet Nam

Email: halinh0508@gmail.com

History

- Received: 2020-11-09

- Accepted: 2021-02-25

- Published: 2021-03-30

DOI : 10.32508/stdj.v24i1.2487

\section{Check for updates}

\section{Copyright}

(c) VNU-HCM Press. This is an openaccess article distributed under the terms of the Creative Commons Attribution 4.0 International license.

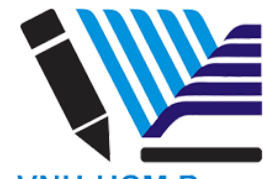

VNU-HCM Press

\section{INTRODUCTION}

Hydroxyapatite (HA, chemical formula $\left.\mathrm{Ca}_{10}\left(\mathrm{PO}_{4}\right)_{6}(\mathrm{OH})_{2}\right)$ is not only a biocompatible, osteoconductive, non-toxic, non-inflammatory, and non-immunogenic agent but also a bioactive agent that has the ability to form a bond with the surrounding bone tissue following implantation. It has been shown to grow and develop similarly to natural bone; its biocompatibility and bioactivity allow the mediation of biological processes ${ }^{1-3}$. HA interacts robustly with tissues on the interface, resulting in stimulation of bone accumulation. After implantation, $\mathrm{HA}$ is gradually dissolved; ionic calcium $\left(\mathrm{Ca}^{2+}\right)$, phosphate $\left(\mathrm{PO}_{4}{ }^{3-}\right)$, and hydroxyl group $\left(\mathrm{OH}^{-}\right)$in the environment are precipitated on the interface, resulting in a new mineral HA layer which attaches to tissues ${ }^{4}$.

The mineral components in animal bone and human bone are similar. Remarkably, bovine bone contains a predominant mass of HA (65-70\%), compared to other animals, and bovine bone generally has a large bone mass and is in abundant supply ${ }^{5}$. Natural HA from bovine bone can be extracted by hydrothermal reactions and calcination at different temperatures. Through this extraction method, organic components in bones can be thermally decomposed and removed. Bone graft from animals can help alleviate the limitations of autologous bone graft ${ }^{6}$, reduce disease contamination, and reduce patient pain.

However, infectious particles (prions) cause Creutzfeldt-Jakob disease in humans and bovine spongiform encephalopathy in cattle. Therefore, the use of bovine material for medical products and devices poses the question as to what degree such a material could be considered free of prions and what the risks are of disease transmission to humans. Therefore, bovine bone processing should be quite well-controlled to avoid disease transmission ${ }^{7}$.

In general, there are two processes at present used to treat the bovine cortical bone. One uses a lowtemperature chemical extraction process, while the other uses a high-temperature $\left(>1000^{\circ} \mathrm{C}\right)$ process to remove residual organic materials. J.A. Toque et al. produced HA from bovine bone powders by calcination without compaction. The powders were calcined at temperatures ranging from $700-1100^{\circ} \mathrm{C}^{8}$. In studies by Nazia Bano et al., the bones were boiled in wa- 
ter for 2-3 hours and dried in an oven at $80^{\circ} \mathrm{C}$ for 72 hours to denaturalize the protein; they were then calcined in a furnace at $600^{\circ} \mathrm{C}$ to $1100^{\circ} \mathrm{C}^{9}$. In a study by Jung Sang Cho et al., bovine bone was boiled in water, further defatted in chloroform, soaked in sodium hypochlorite solution $(4 \%)$, dried at $70^{\circ} \mathrm{C}$, and then heat-treated at $1000^{\circ} \mathrm{C}^{10}$. Furthermore, I. M. Shapiro et al. showed that bovine compact bone could be extracted with chloroform-methanol and then demineralized with ethylenediaminetetraacetic acid (EDTA). The dried demineralized bone was then extracted with acidified chloroform-methanol ${ }^{11}$.

In the study herein, we demonstrate a fabricating process from bovine bone using the combination of chemical and low-thermal decomposition method. The removal of inorganic substances was detected by Fourier-transform infrared (FTIR) spectroscopy. The final multiphase product with the main component of the HA crystals were observed by X-ray powder diffraction method (XRD), scanning electron microscope (SEM), and energy dispersive X-ray (EDX) analysis. The results suggest that HA particles derived from bovine bone by the proposed method did not change the natural microstructure nor bone composition, and thus should be further studied for fabricating advanced composites.

\section{MATERIALS AND METHODS}

\section{Materials}

A femur (plexiform bone) of an adult bovine (which was bought from a local slaughterhouse) was removed of visible substances and tissues on the bone surface. Then, it was smashed into $3 \times 3 \mathrm{~cm}$ sized fragments. Distilled water $(2 \mathrm{x})$, chloroform, ethanol and sodium hypochlorite were provided by Chemsol (Vietnam). The two commercial biomaterials used in this study (Geistlich Bio-Oss ${ }^{\circledR}$ ) were derived from inorganic medullar bovine bone and were used as comparative samples.

\section{HA fabrication method}

The fabrication procedure consisted of three stages: Stage 1: Cleaning and boiling. Bone fragments were immersed in distilled water for $24 \mathrm{~h}$ and water was removed every $12 \mathrm{~h}$. After that, the macroscopic adhering impurities and substances (which included the ligaments and tissues that stick on the bone) were shaved and removed. Raw bone was stewed for $12 \mathrm{~h}$ and water was replaced every $3 \mathrm{~h}$. After boiling, the bone samples were dried for $12 \mathrm{~h}$ at $60^{\circ} \mathrm{C}$ and then subjected to the milling process until a fine powder was generated. Figure 1 shows the flow chart of the cleaning and boiling stage.

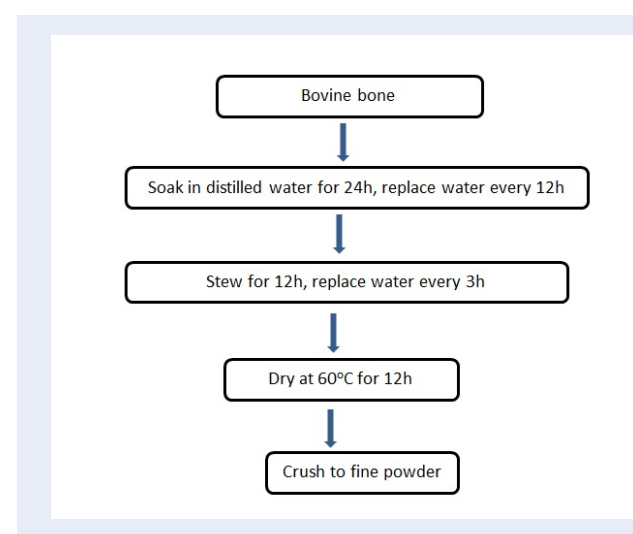

Figure 1: Flow chart of the cleaning stage. Organic components would be largely removed after soak and stew in water. The replace water steps are very important.

Stage 2: Organic solvent and detergent treatment. Each $1 \mathrm{~g}$ of bone grain was treated with $20 \mathrm{~mL}$ of ethanol: chloroform mixture (v/v), with magnetic stirring, for $24 \mathrm{~h}$. The bone was washed using fresh distilled water and dried for $12 \mathrm{~h}$ at $60^{\circ} \mathrm{C}$. Again, grains of bovine bone were treated with $25 \mathrm{~mL}$ sodium hypochlorite ( $\mathrm{NaClO} 4 \%$ ), with magnetic stirring, for $24 \mathrm{~h}$. Bone grains were soaked in distilled water for $72 \mathrm{~h}$ and water was removed every $2 \mathrm{~h}$ during the first $12 \mathrm{~h}$, and then removed every $12 \mathrm{~h}$ for the next $60 \mathrm{~h}$. Ultimately, they were dried at $60^{\circ} \mathrm{C}$ for $12 \mathrm{~h}$.

Stage 3: Thermal treatment. Bone grains were annealed in an electric furnace at $600^{\circ} \mathrm{C}$ for $3 \mathrm{~h}$ and then separated through a strainer with a hole size of 250 $\mu \mathrm{m}$. The final bovine bone-derived HA powder was stored in zipper bags at room temperature. Figure 2 shows the flow chart of the second and third stages.

\section{Characterization methods}

FTIR spectroscopy (Bruker Tensor 27) was used to determine the specific oscillation of $\mathrm{PO}_{4}{ }^{3-}$ and $\mathrm{CO}_{3}{ }^{2-}$ groups and residual organic components in HA particles. For this measurement, the transmission IR spectra were recorded using the $\mathrm{KBr}$ pellet over the range of $4004000 \mathrm{~cm}^{-1}$, with $1 \mathrm{~cm}^{-1}$ resolution averaging over 100 scans.

XRD method (Bruker XRD-D8 Advance, UK) was used to determine the existence of hydroxyapatite and the average size of crystal HAs. Phase analysis was carried out at room temperature using $\mathrm{Cu} \mathrm{K} \alpha$ at a scan speed of $0.5^{\circ} / \mathrm{min}$ and a step scan of $0.02^{\circ}$. The half-width of diffraction peak was calculated by Origin software (OriginLab ${ }^{\circledR}$ ) and the size of crystals was calculated by the Scherrer equation. 


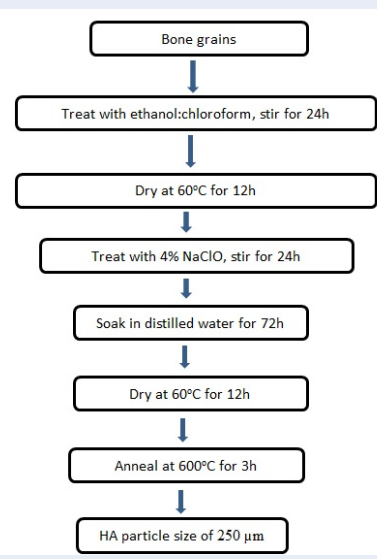

Figure 2: Flow chart of extraction of HA from bovine bone Bone grains are exposured with chemicals to remove organic components and prions. HA crystals would be grown up at $600^{\circ} \mathrm{C}$

The surface morphology and crystal size of the extracted bovine bone HA was observed under optical microscope at 20000 magnification (x20k) and SEM analysis (Hitachi S-4800, Japan) at 20000, 60000 and 120000 magnification (x20k, x60k, x120k). Chemical analysis was also examined by EDX spectroscopy to confirm the components and ratio of different elements in the product.

\section{RESULTS}

\section{General observations}

The color of the product underwent obvious change throughout each stage. Instead of the yellow color (and strong smell) observed at the end of the first stage (Figure 3), the bone was yellowish-white in color (and odorless) at the end of the second stage. The final product was a bright white grain in various sizes (Figure 4).

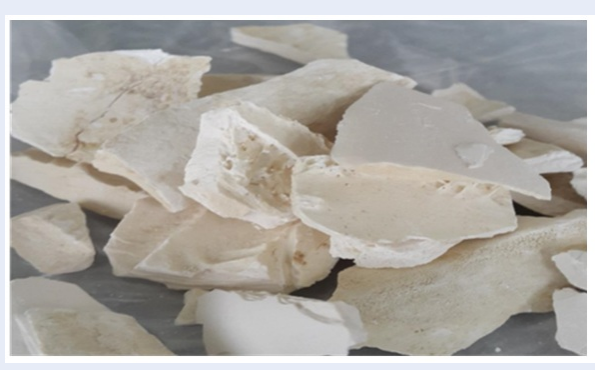

Figure 3: Yellow color and strong smell of bovine bone at the end of the first stage (before the solvent and detergent treatment).

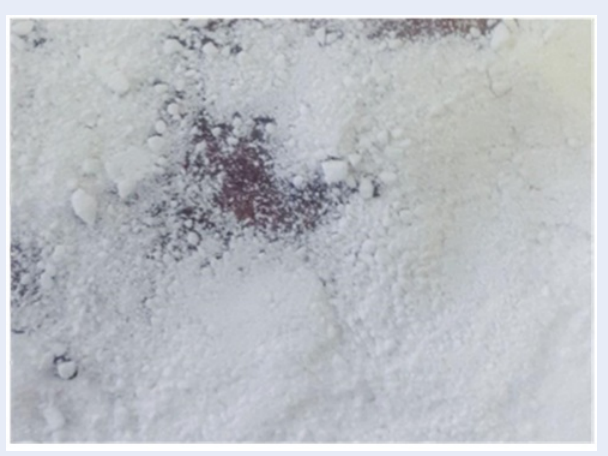

Figure 4: Bovine bone powder at the end of the third stage, shown as a bright white (following incubation at $600{ }^{\circ} \mathrm{C}$ annealing temperature in an electric furnace to remove organic components).

\section{FTIR results}

The FTIR spectrum values of HA for an annealing temperature of at $600^{\circ} \mathrm{C}$ are shown in Figure 6 and Table 1. The specific peaks for phosphate $\left(\mathrm{PO}_{4}{ }^{3-}\right)$ appeared at 567,602 and $1024 \mathrm{~cm}^{-1}$ while the characteristic peaks for carbonate $\left(\mathrm{CO}_{3}{ }^{2-}\right)$ were seen at 874,1416 and $1464 \mathrm{~cm}^{-1}$. The absorption peak of the hydroxyl group $\left(\mathrm{OH}^{-}\right)$was assigned at $3571 \mathrm{~cm}^{-1}$.

The FTIR spectra in Figure 6 (right) shows the alteration of the specific organic peaks in bone particle during the three stages of the procedure. The C-H oscillation peaks associated with the $\mathrm{CH}_{2}$ groups (2926 $\mathrm{cm}^{-1}$ and $2856 \mathrm{~cm}^{-1}$ ), which were observed on the spectrum of bovine bone in the first stage (I), were diminished in the second stage (II) and did not appear on the FTIR spectrum of the third stage (III).

\section{XRD phase results}

The results of the XRD analysis for the treated bone as well as the two comparative samples are shown in Figure 7. Most of the specific peaks for hydroxyapatite in the Bio-Oss/IngeniOs commercial products also corresponded to those of the fabricated HA particles ${ }^{12}$. It was also revealed that there were no significant differences between the commercial HA and extracted HA from bovine bone.

Four prominent XRD peak positions $\left(26.11^{\circ} ; 32.02^{\circ}\right.$; $40.21^{\circ}$; and $49.57^{\circ}$ ) were chosen for calculation of the size of the crystals (Figure 7).

The particle size of HA crystals was not exactly homogenous, but the particle average size was between $15 \mathrm{~nm}$ and $30 \mathrm{~nm}$ (Table 2). 


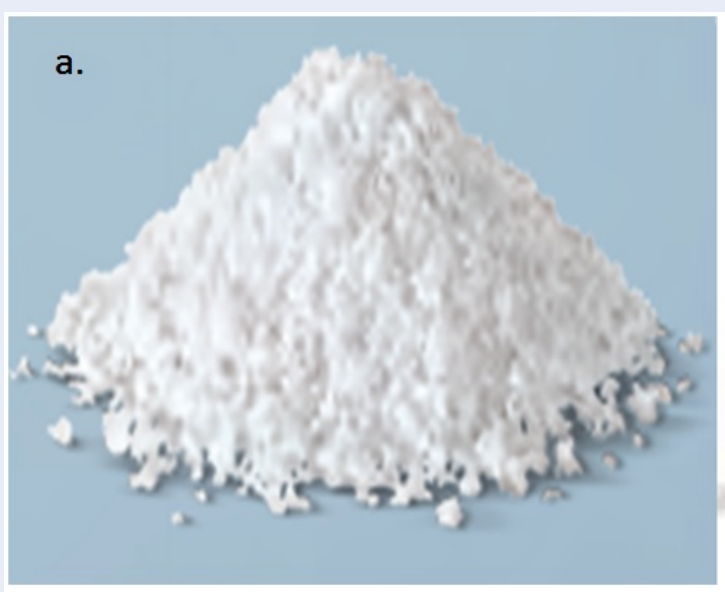

b.

Figure 5: Color of the bovine bone powder compared to that of the commercial sample powders Geistlich Bio-Oss ${ }^{\circledR}$ (a) and IngeniOs ${ }^{\mathrm{TM}}$ HA (b).

Table 1: Peaks of infrared spectra assigned to the functional groups in the FTIR diagram

\begin{tabular}{cccccccc}
\hline $\begin{array}{c}\text { The X-ray wavelength } \\
\left(\mathrm{cm}^{-1}\right)\end{array}$ & 567 & 602 & 874 & 1024 & 1416 & 1464 & 3571 \\
The functional group & $\mathrm{PO}_{4}{ }^{3-}$ & $\mathrm{PO}_{4}{ }^{3-}$ & $\mathrm{CO}_{3}{ }^{2-}$ & $\mathrm{PO}_{4}{ }^{3-}$ & $\mathrm{CO}_{3}{ }^{2-}$ & $\mathrm{CO}_{3}{ }^{2-}$ & $\mathrm{OH}^{-}$ \\
\hline
\end{tabular}

a.

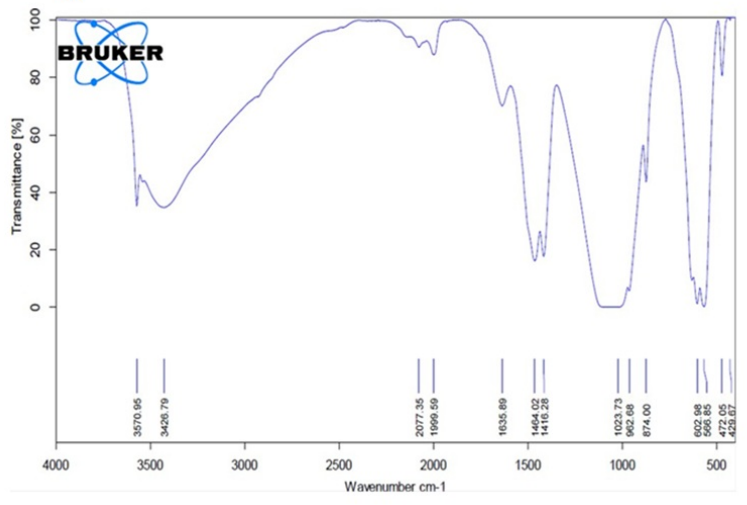

b.

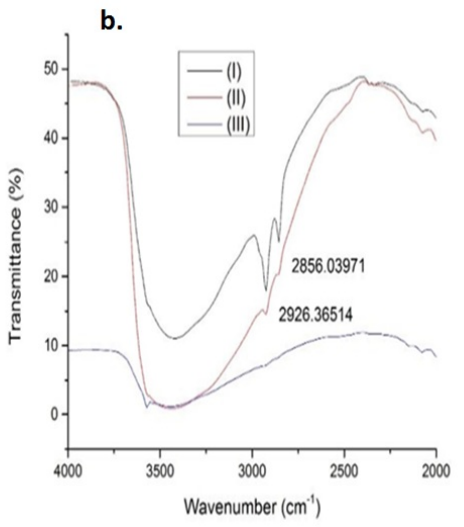

Figure 6: FTIR results for our bovine bone-derived HA product over the range of $400-4000 \mathrm{~cm}^{-1}$ (a). FTIR results over the range of $2000-4000 \mathrm{~cm}^{-1}$ for different stages in the HA fabrication procedure (b) - (I) the first stage (upper line): impurity cleaning and boiling for bovine bone; (II) the second stage (middle line): solvent and detergent treatment for bone grains, and (III) the third stage (lower line): thermal processing for HA powder.

\section{Optical microscopy and SEM results}

Figure 9 shows the porous structure of the extracted micro-HA particles as observed under $\mathrm{x} 20 \mathrm{k}$ magnification under optical microscopy. The particle size of $\mathrm{HA}$ in our treated bone was 30 to $80 \mu \mathrm{m}$, with pore size averaging 2-5 $\mu \mathrm{m}$ in size. The reference SEM images of Geistlich Bio-Oss (left) and IngeniOs ${ }^{\mathrm{TM}} \mathrm{HA}$ (right) were introduced in Figure 10 under magnifi- cation $\mathrm{x} 50 \mathrm{k}$ (https://dental.geistlich-na.com/en-us/pr ofessionals/bone-substitutes/bio-oss/user-benefits).

The SEM micrograph of HA extracted powder obtained from bovine bone is shown in Figure 10 (a, $\mathrm{b}$ and $\mathrm{c}$ ). In Figure 11, the very small hydroxyapatite particles had rod shape-growth on the bone particle (growth in disorientation) and they agglomerated together in some parts. Moreover, the disoriented growth of HA particles on bone particle surface 


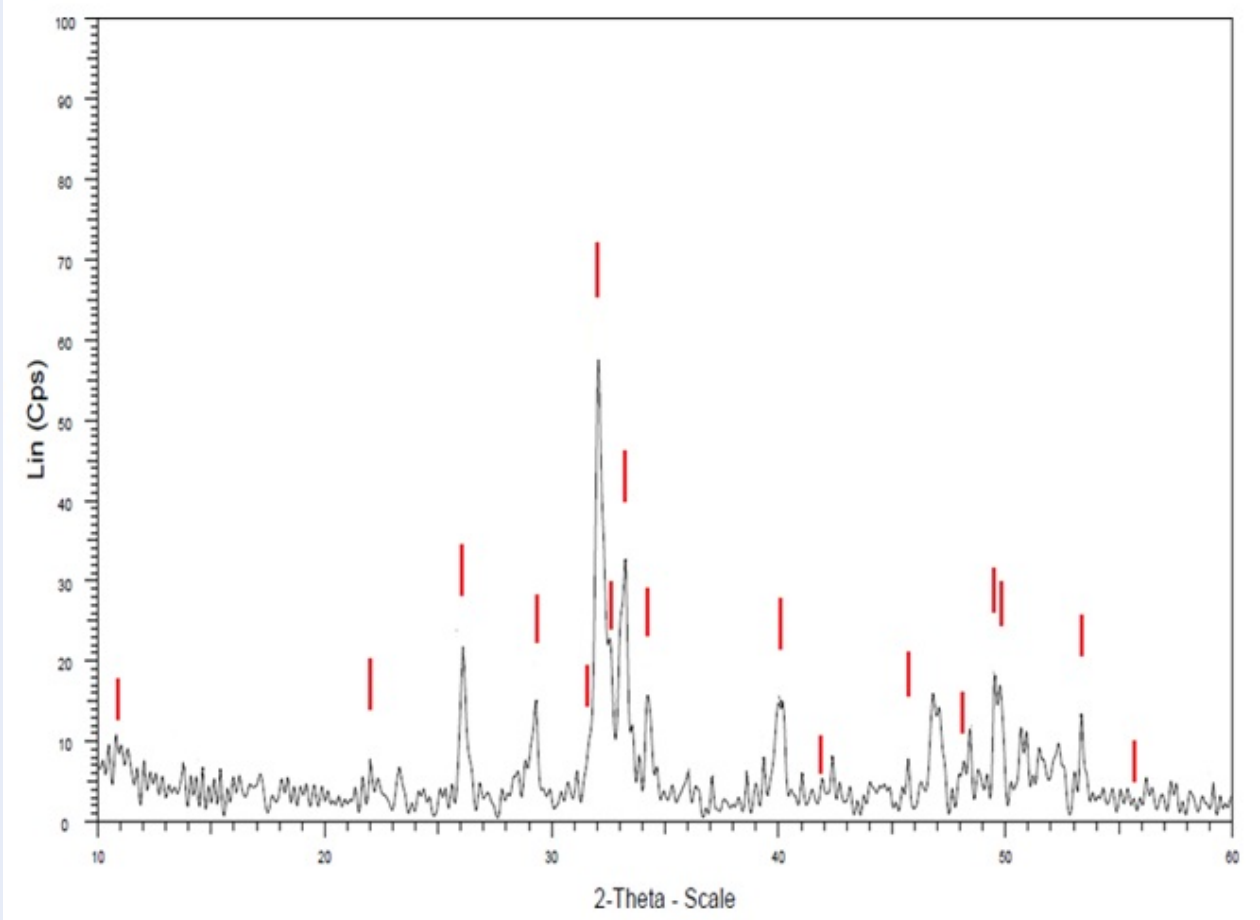

Figure 7: The corresponding XRD peaks for the Bio-Oss/IngeniOs commercial products, as compared to those for the fabricated HA powder. Many values for the fabricated HA particles were the same as those for the commercial HA.

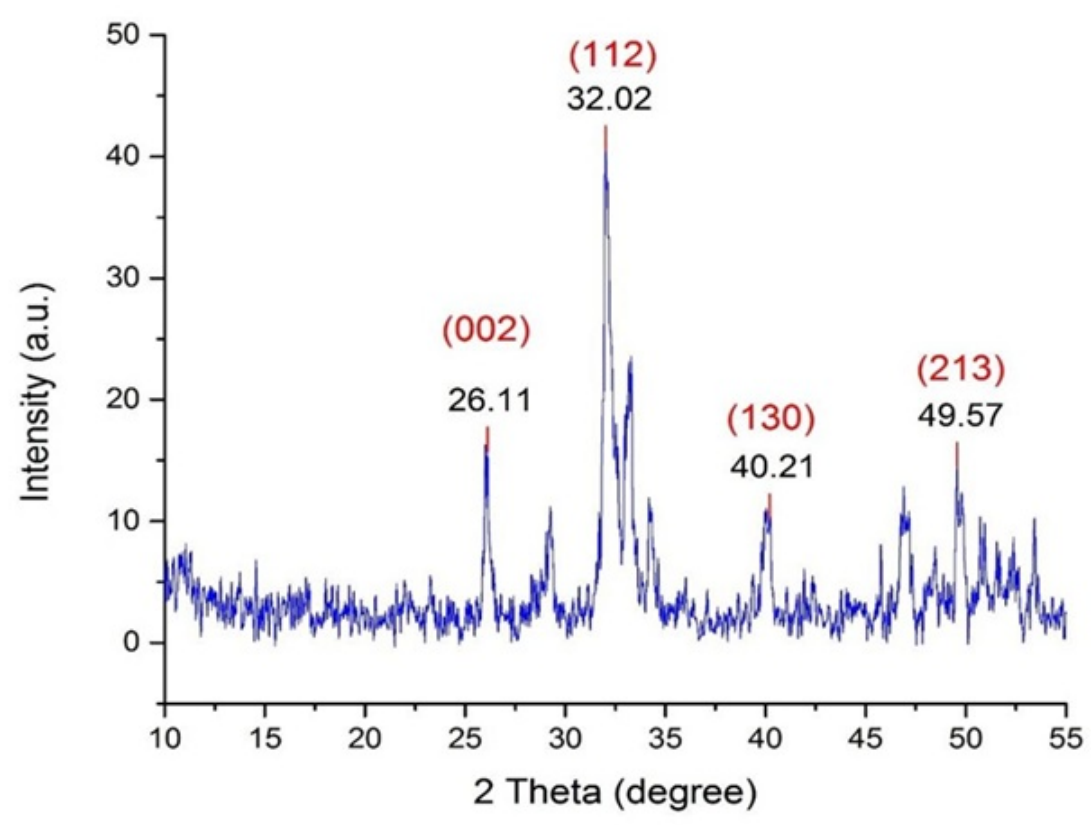

Figure 8: XRD analysis of four selected diffraction peaks with their lattice surface. 
Table 2: Parameter of four selected diffraction peaks and the mean HA particle size of the ordered domain

\begin{tabular}{lcccc}
\hline $\mathbf{2} \Theta$ & $\mathbf{2 6 . 1 1}$ & $\mathbf{3 2 . 0 2}$ & $\mathbf{4 0 . 2 1}$ & $\mathbf{4 9 . 5 7}$ \\
The Bragg angle $(\Theta)$ & 13.06 & 16.01 & 20.11 & 24.79 \\
The dimensionless shape factor $(\mathrm{K})$ & 0.9 & 0.9 & 0.9 & 0.9 \\
The X-ray wavelength $(\lambda)$ & 0.15406 & 0.15406 & 0.15406 & 0.15406 \\
$\begin{array}{l}\text { The line broadening at half the maximum intensity } \\
\text { (D) }\end{array}$ & 0.005 & 0.008 & 0.009 & 0.008 \\
The mean size of the ordered domains $(\mathrm{r}, \mathrm{nm})$ & 28.47 & 18.03 & 16.41 & 19.09 \\
\hline
\end{tabular}

resulted in a more porous structure. The average size of surface HA particles ranged from $50 \mathrm{~nm}$ to $0.2 \mu \mathrm{m}$.

\section{EDX results}

The results of the EDX analysis of extracted bovine bone are not presented in this study. The chemical composition of the material is shown in Table 3. As depicted, components of the HA product consisted of three elements: oxygen, phosphorous and calcium. However, carbon, nitrogen, sodium and magnesium were not detected.

We found that the oxygen, phosphorous and calcium of natural HA extracted from bovine bone were 44.75 , 18.35 and 37.17 wt.\%, according to their atom percentage of $64.65,13.78$ and 21.57 , respectively. The concentrations of oxygen and calcium were higher than that of phosphorus, and the atom ratio of $\mathrm{Ca}$ to $\mathrm{P}$ was 1.56 .

\section{DISCUSSION}

In the study of Eny Kusriniand and Muhammad Sontang, the clean bovine bone samples were defatted in boiling water followed by sun drying to remove the organic substances. Samples were sintered in the range of $500-1400^{\circ} \mathrm{C}$. The bone became black upon sintering at $500^{\circ} \mathrm{C}$, gray at $600-800^{\circ} \mathrm{C}$, and white from 900 to $1100^{\circ} \mathrm{C}^{13}$. In our study, we noted that the color of the bovine bone powder changed visibly before the sintering treatment. Changes in bovine bone powder were related to decomposition of organic matter in the bone powder which indicates the complete removal of organic matrix, such as collagen, protein, polysaccharides and lipids $6,13,14$. Before sintering, the color of the bovine bone powder at room temperature was yellowish white and almost odorless; it changed to bright white upon sintering at $600{ }^{\circ} \mathrm{C}$. Our results are consistent other previous studies. Moreover, our study results emphasized that: (i) the yellow white and odorless products were not yet thermally treated, and (ii) the bright white product was observed at low annealing temperature.
The FTIR spectrum of extracted bovine bone exhibited only the characteristic absorption peaks of HA. The bands in the spectra $(567,602,874,1024,1416$, 1464 , and $3571 \mathrm{~cm}^{-1}$ ) matched the bands in the HA reference spectrum and are in agreement with reported data on $\mathrm{HA}^{15,16}$.

The presence of phosphate $\left(\mathrm{PO}_{4}{ }^{3-}\right)$ in our study was consistent with the study of Greenspan et al. on two comercial products, IngeniOs ${ }^{\mathrm{TM}} \mathrm{HA}$ and BioOss . However, absorption peaks of the hydroxyl group (OH-) which represent HA chemical fomulation could not be seen in the two comercial products, but a clear peak was seen in our final product (at 3571 $\mathrm{cm}^{-1}$ ). In addition, the Bio-Oss material sample showed a peak that is likely associated with a $\mathrm{CO}_{3}{ }^{2-}$ vibration while this peak was completely absent for IngeniOs ${ }^{12}$. Meanwhile, our final product showed many characteristic peaks for $\mathrm{CO}_{3}{ }^{2-}$. Research by Agnieszka Sobczak-Kupiec explained that this difference was due to physicochemical properties of synthetic and natural hydroxyapatite which vary considerably. The differences arise from both a different molar ratio of $\mathrm{Ca} / \mathrm{P}$ and the fact that natural $\mathrm{HA}$ contains $\mathrm{CO}_{3}$ groups and a small amount of foreign elements ${ }^{17}$. Substitutes (e.g. $\mathrm{CO}_{3}{ }^{2-}$ ) are most likely a remnant of the original material and may be decomposed at a higher temperature.

In our study, the diminution and disappearance of C-H oscillation peaks $\left(2926 \mathrm{~cm}^{-1}\right.$ and $\left.2856 \mathrm{~cm}^{-1}\right)$ at the second stage (II) and third stage (III) shows agreement with complete removal of organic composition and that HA crystals appeared in the extracted bone. On the other hand, the partial decomposition of HA to form $\alpha$-tricalcium phosphate ( $\alpha$-TCP), $\beta$-tricalcium phosphate ( $\beta$-TCP) or tetra-calcium phosphate (TTCP) functional groups were not observed in our study.

FT-IR results might confirm that the organic compounds present in the bovine bone were eliminated by the proposed treatment methods. Sintering bovine 


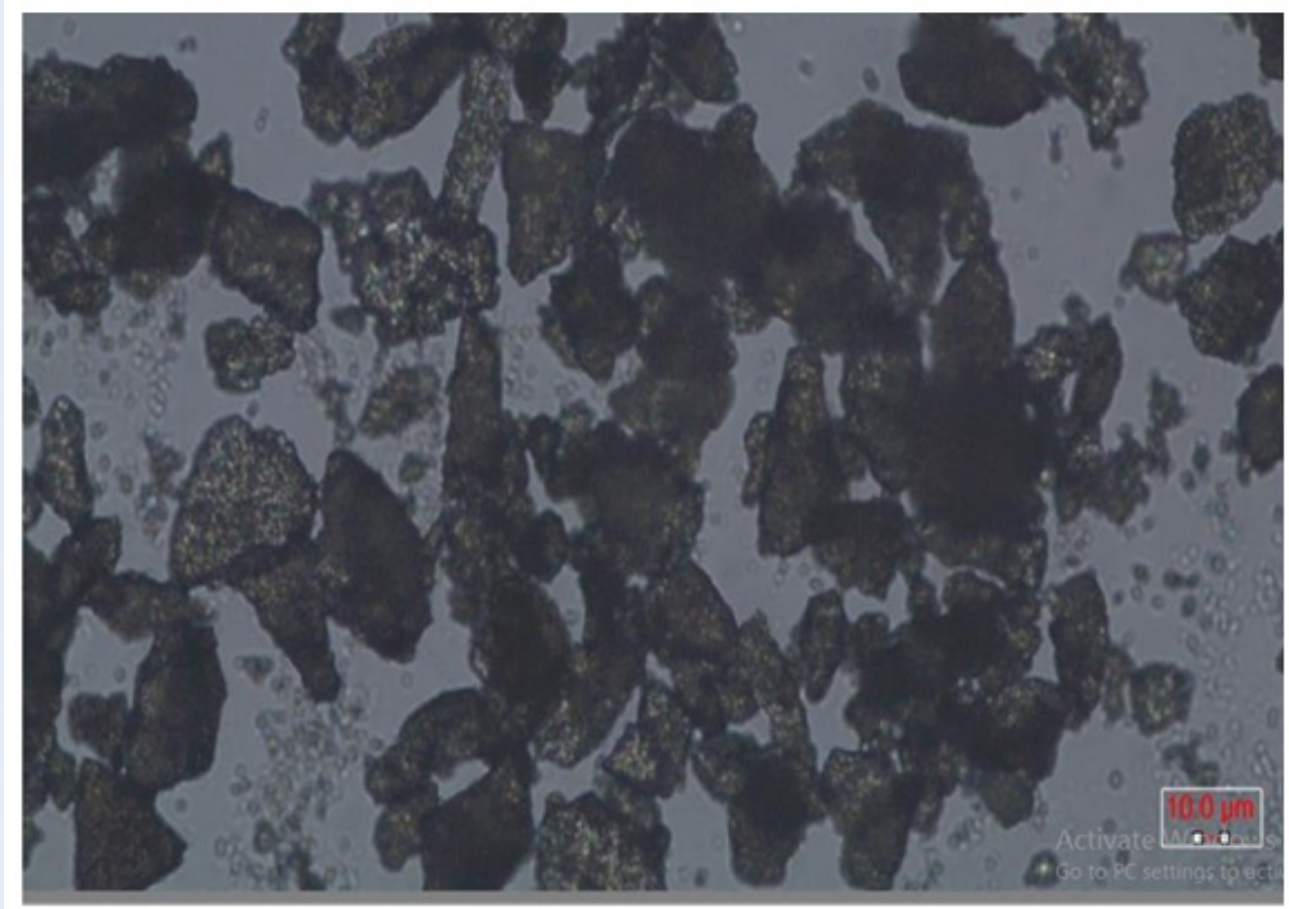

Figure 9: Optical microscopy image of bovine bone powder heated at $600^{\circ} \mathrm{C}$ under x20k magnification. Hydroxyapatite particles with micrometric size (micro-HA) and dense porous structures were obtained.

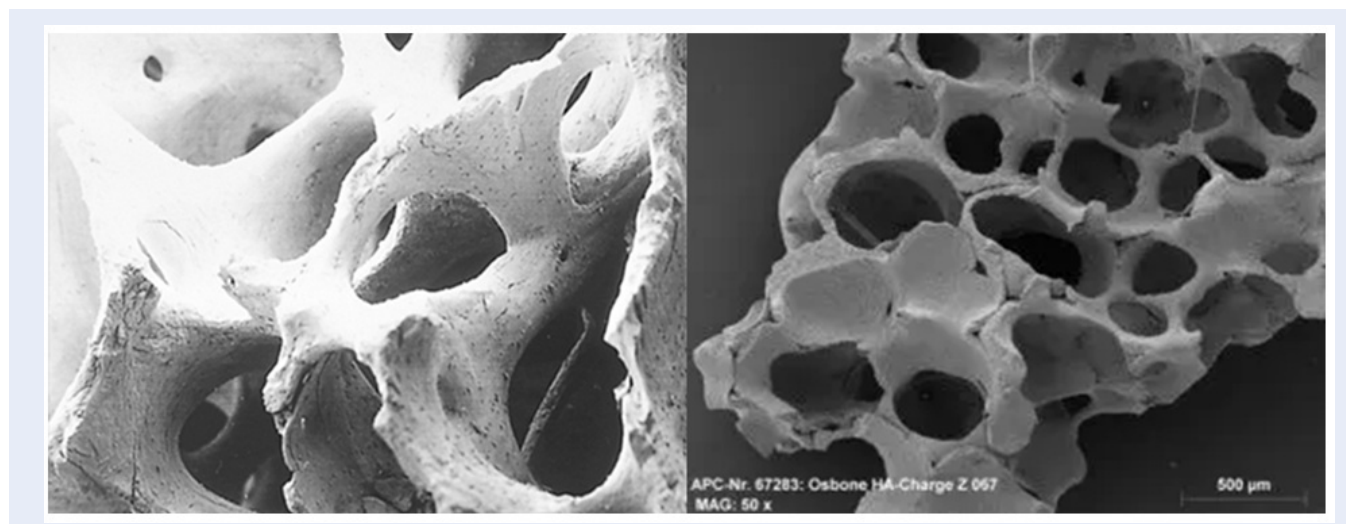

Figure 10: SEM image of Geistlich Bio-Oss (left) and IngeniOs ${ }^{\mathrm{TM}} \mathrm{HA}$ (right) depicting their porous structures (magnification x 50k).

Table 3: The percentage of weight and of atoms of the elements in HA extracted from bovine bone

\begin{tabular}{cccc}
\hline Element & Oxygen $(\mathbf{O})$ & Phosphorus $(\mathbf{P})$ & Calcium (Ca) \\
\% weight & 44.47 & 18.35 & 37.17 \\
\% atom & 64.65 & 13.78 & 21.57 \\
\hline
\end{tabular}



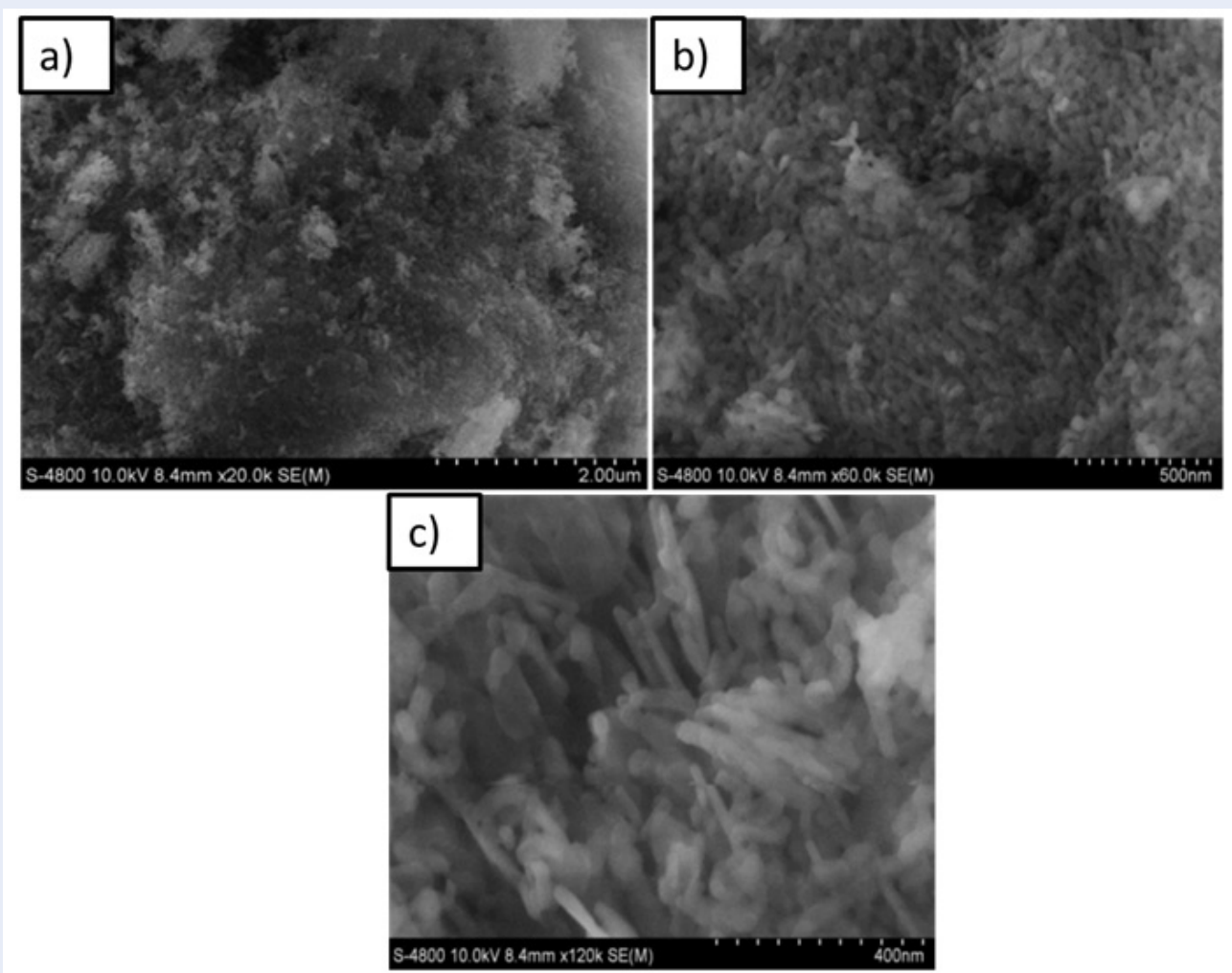

Figure 11: SEM images of irregular bovine particles annealed at $600^{\circ} \mathrm{C}$ under different magnifications. a) x $20 \mathrm{k}$ (very small hydroxyapatite particles are seen growing on the particle surface), b) $x 60 \mathrm{k}$ (HA particles are seen to be of regular size and high density but display disorientation), and c) $\times 120 \mathrm{k}$ (rod-shaped crystal HA particles are seen growing in disorientation in the porous structure).

above $600^{\circ} \mathrm{C}$ might help to obtain pure mineral phase HA.

XRD analysis determines the phase and purity of HA crystals. Barakat et al. (2009) stated that not all the standard hydroxyapatite peaks have been formed or shown in the raw bovine bone due to the presence of fibrous collagen which disperses the X-ray radiation ${ }^{18}$. In our study results, all the peaks corresponding to the standard hydroxyapatite are obvious in the spectra of the extracted bones which illustrates that the treatment processes have produced pure hydroxyapatite. The degree of sharpness of peaks in the extracted bovine bone spectra indicates the crystal formation of the HA and their high purity. The homologous spectrum between treated bone and BioOss ${ }^{\circledR} /$ IngeniOs ${ }^{\mathrm{TM}}$ demonstrates that the proposed process has not affected the chemical structure of HA present in the bovine bone.

Moreover, in our study, the SEM micrograph results show that the particles had irregular shape (mostly rod shape), showed disorientation, and agglomerated together in some regions. The SEM analysis revealed a porous architecture which maintained the spongy structure of natural bone. On the other hand, the size of HA particle $(30-80 \mu \mathrm{m})$ was 10 times larger than the size of the pores $(2-5 \mu \mathrm{m})$; these were in agreement with the particle size and pore ratio for BioOss ${ }^{\circledR}$. The morphology of the HA extracted powder exhibited a porous network due to the removal of organic materials from the bone that are suitable for bone in-growth to form the osseous bed ${ }^{19}$.

The EDX analysis confirmed that the obtained product from the proposed extraction process was hydroxyapatite. $\mathrm{Ca}, \mathrm{P}$ and $\mathrm{O}$ elements in the present study are indeed the major constituents of extracted bone. C.Y. Ooi et al. (2007) showed in their study that the inorganic phases of annealed bovine bone were composed mainly of $\mathrm{Ca}$ and $\mathrm{P}$ as the major constituents, with some minor components comprising of $\mathrm{Na}, \mathrm{Mg}$, $\mathrm{O}$ and $\mathrm{C}$. The $\mathrm{Ca} / \mathrm{P}$ ratio, in their study, of bovine bone annealed at $600^{\circ} \mathrm{C}$ was approximately greater than $2.0^{19}$. According to the chemical formula of the standard hydroxyapatite, the calcium to phosphorous molar ratio is approximately $1.67^{20}$. The $\mathrm{Ca} / \mathrm{P}$ of our 
product is the same as that for Bio-Oss material $(\mathrm{Ca} / \mathrm{P}$ $=1.58)$ while lower than that for IngeniOs material $(\mathrm{Ca} / \mathrm{P}=1.62)^{12}$.

In the study herein, calcium, phosphorous and oxygen elements were found to be the predominant constituents of the treated bone. The $\mathrm{Ca} / \mathrm{P}$ ratio for hydroxyapatite obtained by our study method is 1.56 which is similar to that for Bio-Oss material (1.58) and which lies within the acceptable range for hydroxyapatite $^{20}$.

\section{CONCLUSION}

Calcination is one of important processes which affect the characteristics, efficiency, pure phase and size of the HA material. The combination of chemical solvent heating can lead to energy reduction or elimination, lowered cost and higher performance. Our study confirms that bovine bone HA can be extracted from the combination of methods which includes physical and chemical means, and sintering upon $600^{\circ} \mathrm{C}$. The organic components were completely removed out of the bone, resulting in interconnected porous structures of the bone particle. Our fabrication method is, therefore, practical for producing HA from bovine bone.

\section{ABBREVIATION}

HA: Hydroxyapatite

FTIR: Fourier Transform Infrared

XRD: the X-ray powder diffraction method

SEM: Scanning Electron Microscope

EDX: energy dispersive X-ray spectroscopy

TCP: tricalcium phosphate

\section{ACKNOWLEDGMENT}

This research is funded by Dr. Cao Huu Tien, Faculty of Dentistry in Pham Ngoc Thach University of Medicine.

\section{CONFLICT OF INTEREST}

The authors declare they have no conflicts of interest.

\section{REFERENCES}

1. Thrivikraman G, Madras G, Basu B. In vitro/In vivo assessment and mechanisms of toxicity of bioceramic materials and its wear particulates. RSC Advances. 2014;4(25). Available from: https://doi.org/10.1039/c3ra44483j.

2. Fahmy MD, Jazayeri HE, Razavi M, Masri R, Tayebi LJJoP. Three-dimensional bioprinting materials with potential application in preprosthetic surgery. 2016;25(4):310-318. PMID: 26855004. Available from: https://doi.org/10.1111/jopr.12431.

3. Dhandayuthapani B, Yoshida Y, Maekawa T, Kumar DS. Polymeric Scaffolds in Tissue Engineering Application: A Review. International Journal of Polymer Science. 2011;2011:1-19. Available from: https://doi.org/10.1155/2011/290602.
4. Nayak AKJIJoCR. Hydroxyapatite synthesis methodologies: an overview. 2010;2(2):903-907.

5. Accorsi-Mendonça T, Conz MB, Barros TC, Sena LÁd, Soares GdA, Granjeiro JMJBor. Physicochemical characterization of two deproteinized bovine xenografts. 2008;22(1):5-10. PMID: 18425238. Available from: https://doi.org/10.1590/S180683242008000100002.

6. Rana M, Akhtar N, Rahman S, Jamil H, Asaduzzaman SJIJCAM. Extraction of hydroxyapatite from bovine and human cortical bone by thermal decomposition and effect of gamma radiation: a comparative study. 2017;8(3):1-10. Available from: https://doi.org/10.15406/ijcam.2017.07.00263.

7. Wenz B, Oesch B, Horst MJB. Analysis of the risk of transmitting bovine spongiform encephalopathy through bone grafts derived from bovine bone. 2001;22(12):1599-1606. Available from: https://doi.org/10.1016/S0142-9612(00)00312-4.

8. Toque JA, Herliansyah MK, Hamdi M, Ide-Ektessabi A, Wildan MW. The effect of sample preparation and calcination temperature on the production of hydroxyapatite from bovine bone powders. 3rd Kuala Lumpur International Conference on Biomedical Engineering 2006. IFMBE Proceedings. 2007;p. 152-155. Available from: https://doi.org/10.1007/978-3-54068017-8_39.

9. Bano N, Jikan SS, Basri H, Bakar SAA, Nuhu AHJJoS, Technology. Natural hydroxyapatite extracted from bovine bone. 2017;9(2).

10. Cho JS, Kim HS, Um SH, Rhee SH. Preparation of a novel anorganic bovine bone xenograft with enhanced bioactivity and osteoconductivity. J Biomed Mater Res B Appl Biomater. 2013;101(5):855-869. PMID: 23359483. Available from: https: //doi.org/10.1002/jbm.b.32890.

11. Shapiro IJAoob. The neutral lipids of bovine bone. 1971;16(4):411-421. Available from: https://doi.org/10. 1016/0003-9969(71)90165-8.

12. Greenspan DCJZDI. Comparison of a synthetic and bovine derived hydroxyapatite bone graft substitute. 2012;p. 1-4.

13. Kusrini E, Sontang M. Characterization of x-ray diffraction and electron spin resonance: Effects of sintering time and temperature on bovine hydroxyapatite. Radiation Physics and Chemistry. 2012;81(2):118-125. Available from: https://doi.org/10. 1016/j.radphyschem.2011.10.006.

14. Herliansyah MK, Hamdi M, Ide-Ektessabi A, Wildan MW, Toque $J A$. The influence of sintering temperature on the properties of compacted bovine hydroxyapatite. Materials Science and Engineering: C. 2009;29(5):1674-1680. Available from: https: //doi.org/10.1016/j.msec.2009.01.007.

15. Joschek S, Nies B, Krotz R, Göpferich AJB. Chemical and physicochemical characterization of porous hydroxyapatite ceramics made of natural bone. 2000;21(16):1645-1658. Available from: https://doi.org/10.1016/S0142-9612(00)00036-3.

16. Walters M, Leung Y, Blumenthal N, Konsker K, LeGeros RJJoib. A Raman and infrared spectroscopic investigation of biological hydroxyapatite. 1990;39(3):193-200. Available from: https: //doi.org/10.1016/0162-0134(90)84002-7.

17. Sobczak-Kupiec A, Wzorek Z. The influence of calcination parameters on free calcium oxide content in natural hydroxyapatite. Ceramics International. 2012;38(1):641-647. Available from: https://doi.org/10.1016/j.ceramint.2011.06.065.

18. Barakat NAM, Khil MS, Omran AM, Sheikh FA, Kim HY. Extraction of pure natural hydroxyapatite from the bovine bones bio waste by three different methods. Journal of Materials Processing Technology. 2009;209(7):3408-3415. Available from: https://doi.org/10.1016/j.jmatprotec.2008.07.040.

19. Ooi CY, Hamdi M, Ramesh S. Properties of hydroxyapatite produced by annealing of bovine bone. Ceramics International. 2007;33(7):1171-1177. Available from: https://doi.org/ 10.1016/j.ceramint.2006.04.001.

20. Francis MD, Webb NCJCtr. Hydroxyapatite formation from a hydrated calcium monohydrogen phosphate precursor. 1970;6(1):335-342. PMID: 5553333. Available from: https: //doi.org/10.1007/BF02196214. 